\title{
Caracterização molecular através da técnica fAFLP de isolados de Diaporthe citri
}

\author{
Márcia de Holanda Nozaki ${ }^{*}$, Margarete Camargo ${ }^{1}$, Eliana Gertrudes Macedo Lemos ${ }^{2}$, \\ Ana Paula de Andrade Aukar ${ }^{2}$, Modesto Barreto $^{1}$
}

${ }^{1}$ Departamento de Fitossanidade, FCAV/UNESP, Via de Acesso Prof. Paulo Donato Castellane km 5, s/n ${ }^{\circ}, 14.884-900$, Jaboticabal, SP; ${ }^{2}$ Departamento de Tecnologia, FCAV/UNESP, Jaboticabal, SP.

* Parte da dissertação de mestrado da primeira autora.

Data de chegada: 06/05/2004. Aceito para publicação em: 20/05/2005.

\begin{abstract}
Nozaki, M. H.; Camargo, M.; Lemos, E. G. M.; Aukar, A.P.A.; Barreto, M. Molecular characterization of Diaporthe citri isolates using fAFLP technique. Summa Phytopathologica, v.32, n. 2, p.147-150, 2006.

Citriculture is a market in expansion specially in Sao Paulo State, whose importance in the economy is already recognized. Like any other cultivated species, the increase of planted areas contributes to an increase in disease problems. Thus, many diseases affect citrus species, including melanose, caused by Diaporthe citri (Wolf.), to which most commercial varieties are susceptible to the disease. Knowledge of the intra-specific diversity is important when selecting varieties for resistance. This study evaluated the genetic variability

among Diaporthe citri isolates, obtained from different geographical regions, varieties, and parts of the plant using molecular markers. Amplified Fragment Length Polymorphism (AFLP) markers were used to characterize ten isolates of this pathogen. Genomic DNAs extracted from mycelial mass were used in amplification reactions. fAFLP allowed separation of the isolates into four distinct groups. However, genetic similarity analysis did not group isolates by location, variety or part of the plant.
\end{abstract}

Additional keywords: melanose, polymorphism, genetic variability, citrus.

\section{RESUMO}

Nozaki, M. H.; Camargo, M.; Lemos, E. G. M.; Aukar, A.P.A.; Barreto, M. Caracterização molecular através da técnica fAFLP de isolados de Diaporthe citri. Summa Phytopathologica, v.32, n. 2, p.147-150, 2006.

A citricultura é um mercado em expansão, principalmente no Estado de São Paulo, cuja importância na balança comercial já é reconhecida. Como em qualquer espécie cultivada, o crescimento das áreas de cultivo favorecem também o crescimento de problemas fitossanitários. Desta forma, as espécies de citros são afetadas por diversas doenças destacando-se entre elas a melanose, causada por Diaporthe citri (Wolf.), à qual a grande maioria das variedades comerciais são suscetíveis. O conhecimento da diversidade intra-específica é de grande importância, já que esta poderá auxiliar na seleção de variedades com resistência. O objetivo deste trabalho foi avaliar a variabilidade gené- tica em isolados de Diaporthe citri, originários de diferentes locais, variedades e partes da planta, utilizando marcadores moleculares. Marcadores do tipo AFLP (Amplified Fragment Length Polymorphism) foram utilizados para caracterização de dez isolados do patógeno. Os DNAs genômicos extraídos da massa micelial foram utilizados nas reações de amplificação. A técnica fluorescent AFLP permitiu a distinção dos isolados estudados, tendo sido classificados em quatro grupos distintos. Contudo, estes grupos não foram formados em razão da região geográfica, parte da planta ou variedade.

Palavras-chave adicionais: melanose, polimorfismo, variabilidade genética, citros.

A melanose, causada por Diaporthe citri (Wolf.), fase anamórfica Phomopsis citri, ocasiona em certos períodos perdas econômicas financeiras significativas, principalmente em frutos muito manchados, resultando em perda ou queda na produção de suco cítrico $(3,11,15,16)$.

Os sintomas da doença estão presentes em folhas, ramos e frutos. Nas folhas, as lesões inicialmente são de tamanhos menores, com coloração de marrom-escura a pretas. Sintomas em ramos novos e verdes são aparentemente similares aos da folha, com exceção de serem menores e menos salientes. Em frutos, as lesões iniciais são manchas pequenas, circulares e de coloração marrom que se tornam pontos pretos, sendo ásperos 
ao tato $(4,11)$.

Os esporos do fungo, disseminados com respingos de chuva, são produzidos em estruturas de frutificação denominadas picnídios, que se desenvolvem apenas em material vegetal morto. Como formas de controle, deve-se remover material vegetal morto da área, além de utilizar fungicidas cúpricos $(6,11,16)$.

A despeito destas definições genéricas, a identificação de espécies de Diaporthe é geralmente incerta pelo fato de muitos isolados apresentarem apenas conídios alfa. Apenas uma dentre quatro espécies é conhecida por produzir conídios beta. A maioria dos isolados de Diaporthe não está associada ao seu estágio teleomórfico, ao seu substrato natural ou cultura. $\mathrm{O}$ teleomorfo Diaporthe tem sido descrito para apenas aproximadamente $20 \%$ das espécies de Phomopsis. As variações morfológicas e culturais dentro de um isolado podem ser tão amplas quanto dentre isolados (12). Geralmente, essas características têm sido inadequadas para delimitar claramente espécies de Diaporthe (19). Com isso, a classificação mais precisa de determinados grupos de fungos fitopatogênicos utilizando métodos clássicos tem sido difícil, gerando várias denominações para uma mesma espécie $(5,7)$.

Durante os últimos anos, o conhecimento da estrutura genética de populações de fitopatógenos tem se tornado necessário para a implementação de estratégias de controle efetivas. Apesar do número de estudos com fungos ter crescido significativamente, observa-se que os trabalhos têm enfocado um número restrito de fitopatógenos.

Os marcadores moleculares vêm sendo utilizados para caracterizar diversidade genética inter e intra espécies de patógenos sem interferência do meio ambiente $(1,2,7,10)$. Na maioria dos estudos de genética de populações, utiliza-se marcadores genéticos que são seletivamente neutros, altamente informativos, reproduzíveis e relativamente fáceis de serem estudados (9).

Dentre os diversos marcadores, Vos et al. (20) destaca o uso da técnica mais recente de Fragmentos Polimórficos de DNA Amplificados (AFLP) baseada na reação da polimerase em cadeia (PCR). Combina-se nesta técnica os princípios de RFLP e PCR, onde uma subamostra de fragmentos produzidos pela restrição do DNA são amplificados seletivamente. São utilizados oligonucleotídeos complementares às seqüências ligadas a cada extremo do DNA digerido. O polimorfismo é detectado pela presença ou ausência de fragmentos e são normalmente de herança dominante (8).

Com esta técnica, pode-se detectar uma variação considerável do genoma, através do número de produtos amplificados apenas com a combinação de enzimas (14). O marcador AFLP analisa a presença ou ausência de sítios de enzimas de restrição e as sequiências polimórficas adjacentes a esses sítios. Uma das maiores vantagens desta técnica é que somente uma reação permite identificar até 50 loci em tempo reduzido. Estes são tão reproduzíveis quanto em RFLP, pois são insensíveis às condições da reação. Porém, deve-se ressaltar que ambas as técnicas requerem DNA de boa qualidade para o processo de digestão com enzimas de restrição $(8,17)$.

Zhang et al. (21) utilizaram características morfológicas para diferenciar isolados de Diaporthe phaseolorum e Phomopsis longicolla, além de PCR-RFLP, para separar os isolados em seis grupos filogenéticos diferentes.

Uddin \& Stevenson (18) verificaram que isolados de Pho- mopsis spp. obtidos de pessegueiro não apresentaram diferença quanto a características morfológicas e moleculares, seqüências de nucleotídeos e virulência em plantas.

Pode-se observar que alguns grupos de fungos fitopatogênicos, como os do complexo Diaporthe/Phomopsis, são historicamente difíceis de identificar através de métodos convencionais, visto que as características morfológicas são comumente variáveis, dificultando assim o estabelecimento de uma categoria taxonômica adequada. Há, portanto, necessidade de aplicação de métodos complementares como auxílio na identificação das espécies $(5,21)$.

O presente trabalho teve como objetivo caracterizar isolados de Diaporthe citri através da técnica fAFLP.

\section{MATERIAL E MÉTODOS}

Para obtenção de culturas puras, dez isolados monospóricos de Diaporthe citri obtidos de diferentes partes de plantas cítricas das regiões de Conchal, Monte Alto e Jaboticabal/SP, com sintomas típicos de melanose, foram utilizados no experimento.

Quadro 1. Relação de isolados de Diaporthe citri estudados na caracterização molecular e suas respectivas origens.

\begin{tabular}{cccc}
\hline Isolados & Planta & Órgão & Local \\
\hline PC1 & Laranja & Ramo & Jaboticabal - SP \\
PC2 & Limão & Ramo & Conchal - SP \\
PC3 & Laranja & Folha & Jaboticabal - SP \\
PC4 & Limão & Ramo & Conchal - SP \\
PC5 & Laranja & Ramo & Conchal - SP \\
PC6 & Laranja caipira & Fruto & Jaboticabal - SP \\
PC7 & Limão galelo & Folha & Jaboticabal - SP \\
PC9 & Limão Tahiti & Ramo & Jaboticabal - SP \\
PC10 & Limão Tahiti & Folha & Jaboticabal - SP \\
PC11 & Limão Feminelo & Fruto & Monte Alto - SP
\end{tabular}

Os isolados foram cultivados em placas de Petri em meio de cultura batata-dextrose-ágar (BDA) e incubados a $22 \pm 2^{\circ} \mathrm{C} \mathrm{com}$ regime de alternância luminosa $12 \mathrm{~h} / 12 \mathrm{~h}$ por um período de 15 dias. Após este período, fragmentos de micélio retirados das margens das colônias foram transferidos para erlenmeyers com $50 \mathrm{~mL}$ de meio líquido batata-dextrose (BD), incubados por 14 dias, sem agitação, nas mesmas condições anteriores.

Após incubação, a massa micelial foi coletada pela filtragem das culturas em filtro de Buchner (adaptado) acoplado à bomba de vácuo. Após completamente secas, as culturas foram submetidas à maceração em nitrogênio líquido. Parte do micélio obtido foi conservado congelado e o restante armazenado para extração de DNA.

Os DNAs fúngicos foram extraídos pelo método de Möller et al. (10) para fungos filamentosos (modificado), como segue. Ao micélio do fungo previamente macerado foram adicionados TES (solução tampão) e proteinase K (10 $\mu \mathrm{L} /$ amostra). Logo em seguida, adicionou-se $10 \mu \mathrm{L}$ RNAse em cada amostra e ajustouse a concentração salina da solução para $1,4 \mathrm{M}$ com $\mathrm{NaCl} 5 \mathrm{M}$. 
Por fim, adiciou-se SEVAG (solução de precipitação). Ao término de cada procedimento as amostras foram incubadas a diferentes temperaturas e períodos de tempo $\left(37^{\circ} \mathrm{C}\right.$ por 1 hora; $65^{\circ} \mathrm{C}$ por 10 minutos; $-10^{\circ} \mathrm{C}$ por 30 minutos). A solução final foi submetida à centrifugação (10000 rpm por 10 minutos) e o sobrenadante resultante foi transferido para outro tubo e neste, adicionou-se $\mathrm{NH}_{4} \mathrm{Ac} 5 \mathrm{M}$ e as amostras foram incubadas em gelo. Após incubação, as amostras foram submetidas a nova centrifugação, transferindo o sobrenadante resultante, como descrito anteriormente. Neste novo tubo adicionou-se 0,55 do volume de isopropanol absoluto para precipitar o DNA, levando as amostras para incubação $\mathrm{a}-80^{\circ} \mathrm{C}$ por 30 minutos e centrifugando-as posteriormente a $10000 \mathrm{rpm}$ por 5 minutos. O sobrenadante resultante foi retirado, lavado com etanol $70 \%$, seco e dissolvido em TE. O DNA extraído foi então armazenado a $80^{\circ} \mathrm{C}$.

Antes do uso em fAFLP, o DNA de cada isolado foi quantificado em Biofotômetro (Eppendorf), nos comprimentos de onda de 260 e $280 \mathrm{~nm}$ e em gel de agarose $0,8 \%$, visando verificar a integridade do material.

Os fragmentos foram visualizados sob luz UV e documentados em fotodocumentador modelo GEL DOC 1000 (BIO-RAD).

Para o ensaio de fAFLP, empregou-se o kit AFLP Plant Mapping (PE Aplied Biosystems), seguindo as instruções do fabricante.

O DNA fúngico (500 ng) foi digerido com as enzimas EcoRI e $M s e I$ e as enzimas foram inativadas. Os fragmentos resultantes foram ligados aos adaptadores (Applied Biosystems). Os fragmentos acoplados aos adaptadores foram amplificados (amplificação pré-seletiva) por PCR utilizando os primers EcoRI e MseI. O produto resultante foi analisado através de eletroforese em gel de agarose para determinar o tamanho dos fragmentos amplificados. A reação resultante serviu de "template" (modelo) para a amplificação (seletiva), em condição semelhante à anterior utilizando os mesmos primers, porém com adição de 3 bases na extremidade 3' e marcação fluorescente. As amostras depois de desnaturadas foram levadas para gel seqüenciador e visualizadas no equipamento ABI PRISM 377 DNA Sequencer (Applied Biosystems).

A análise dos dados foi conduzida através do software GeneScan 3.1 (Perkin-Elmer) utilizado para determinar o comprimento dos fragmentos da amostra pela comparação com DNA de tamanho padrão. Foram gerados eletroferogramas dos fragmentos com tamanhos de 50 a 500 pares de base. Com os perfis de fAFLP obtidos de cada isolado foi montada uma matriz binária através do software Genotyper 2.5 (Perkin-Elmer). A matriz foi utilizada para a construção da árvore filogenética através do software Phylip 3.2. O dendograma foi gerado por UPMGA ilustrando a distância genética entre as regiões.

\section{RESULTADOS E DISCUSSÃO}

Dentre os primers testados, ACA-CTA (FAM), ACG-CTA (JOE) e AGC-CTA (NED), foi selecionado o primer FAM pois apenas este amplificou para todos os isolados utilizados, resultando na produção de 28 bandas polimórficas, de um total de 50 , variando de 50 a 500pb.

A Figura 1 ilustra os eletroferogramas obtidos com o primer fAFLP ACA-CTA (FAM) para sete isolados de P. citri.

A partir dos dados obtidos, construiu-se um dendograma
(Figura 2), no qual, demonstrou-se nenhuma ligação entre os isolados tanto pelas partes das plantas quanto pelas variedades das quais foram isolados. Não foi possível, portanto, separar os isolados em grupos de acordo com sua origem. Com isso, na análise de agrupamento dos isolados, foram distinguidos quatro grupos: 1 (PC1), 2 (PC2, PC3), 3 (PC4, PC6, PC7, PC9, PC11) e 4 (PC5, PC10).

Resultados semelhantes foram obtidos por Says-Lesage et al. (13) avaliando isolados de Phomopsis de girassol. Os isolados não apresentaram relação entre variabilidade molecular, região geográfica, agressividade ou formação de peritécio.

Gurgel et al. (5) utilizando padrões de esterase para diferenciar isolados de Phomopsis spp., também encontraram distâncias na análise de agrupamento representando, de acordo com

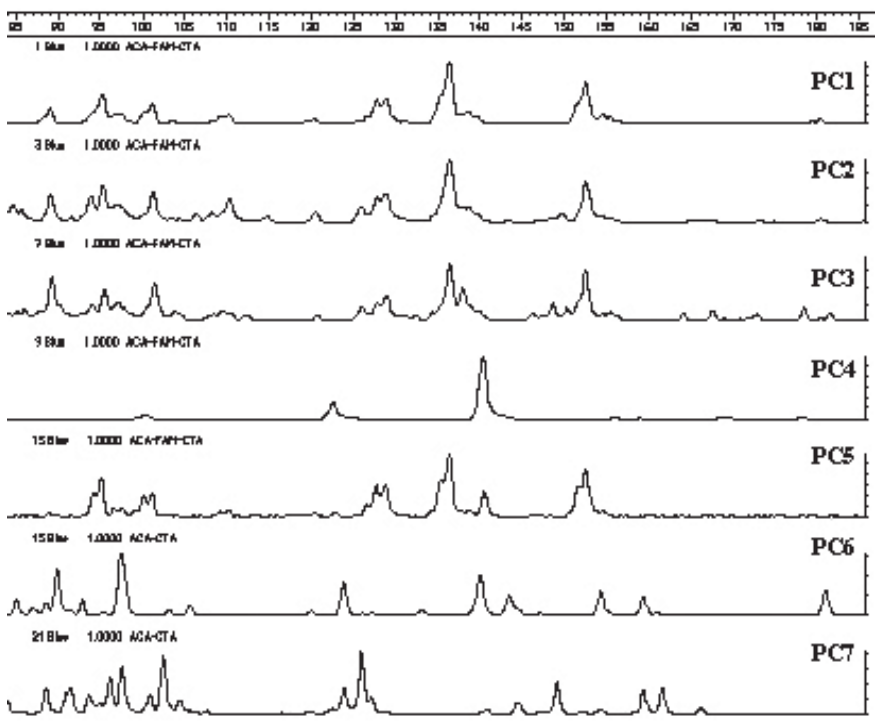

Figura 1. Eletroferogramas de sete isolados de Diaporthe citri referentes ao marcador de 50 - $500 \mathrm{pb}$, obtidos com o primer ACA-CTA (FAM), presente nos isolados de Diaporthe citri.

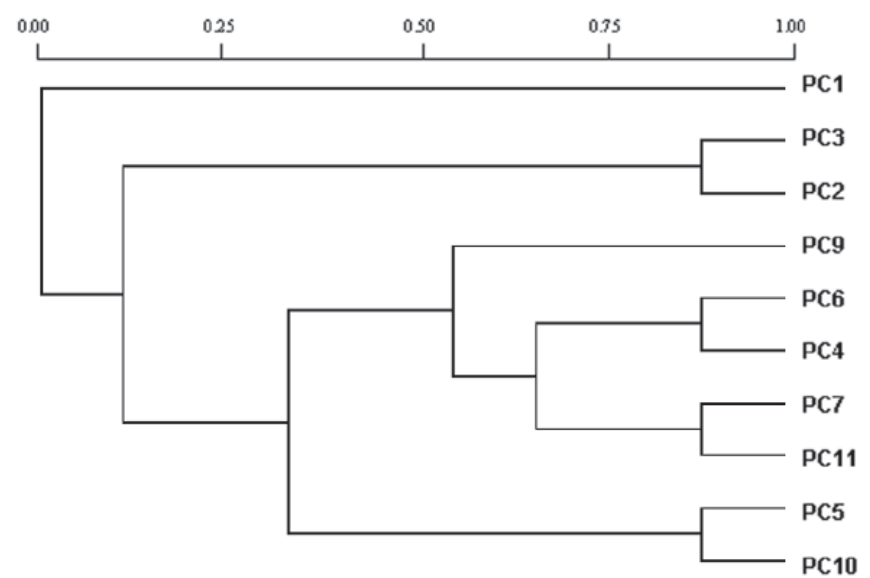

Figura 2. Dendograma construído pelo software Phylip versão 3.2, relacionando todos os isolados de Diaporthe citri, analisados com o "primer" ACA-CTA (FAM) selecionado para identificação de diferenças filogenéticas. 
os autores, possíveis formas fisiológicas ou raças diferentes. As diferenças encontradas em $D$. citri, portanto, também sugerem a ocorrência de f.sp. ou raças.

Uddin \& Stevenson (18) analisando isolados de Phomopsis de pêssego também não verificaram diferença significativa de virulência.

Este fator (virulência) pode ser possivelmente explicado pelo fato da diversidade do gene ser afetada pela idade e tamanho da população e seleção ou ainda por outros fatores (9).

Neste ensaio verificou-se que o Kit para fAFLP desenvolvido pela Applied Biosystems para a análise de plantas também pode ser aplicado para a caracterização de fungos.

A análise dos resultados permitiu concluir que marcadores fAFLP permitiram acessar a diversidade entre os isolados de $D$. citri, porém, o presente estudo mostra diferenças genéticas entre isolados de $D$. citri que são independentes da região, parte da planta ou variedade a partir das quais foram obtidos.

\section{REFERÊNCIAS BIBLIOGRÁFICAS}

1. Becerra, V.; Paredes, M. Uso de marcadores bioquímicos y moleculares en estudios de diversidad genética. Agricultura Técnica, Madri, v.60, n.3, p.270-281, 2000.

2. Brown, J.K.M. The choice of molecular marker methods for population genetic studies of plant pathogens. New Phytopathology, London, n. 133, 1996. p. 183-195, 1996.

3. Bushong, P.M.; Timmer, L.W. Evaluation of postinfection control of citrus scab and melanose with benomyl, fenbuconazole and azoxystrobin. Plant Disease, Saint Paul, v.84, n.11, p.1246-1249, 2000.

4. Futch, S.H.; Timmer, L.W. A guide to citrus disease identification. Florida: Horticultural Sciences Departament, Florida Cooperative Extension Service, Institute of Food and Agricultural Sciences, University of Florida, 2001. 7p. (Extension publications, HS-798).

5. Gurgel, L.M.S.; Menezes, M.; Coelho, R.S.B. Diferenciação de Diaporthe anacardii e Diaporthe mangiferae por padrões eletroforéticos de proteínas e isoenzimas. Summa Phytopathologica, Jaboticabal, v.26, n.4. p.435-440, 2000.

6. Knapp, J.L. 2000 Florida citrus pest management guide. Florida: Institute of Food and Agriculture Science, University of Florida. (Publication, SP43), 2000

7. Leal-Bertioli, S.C. de M. O enfoque molecular na sistemática de fungos. RAPP, Brasília, v.6, pp.197-229, 1998.

8. Majer, D.; Mithen, R.; Lewis, B.G.; Vos, P.; Oliver, R.P. The use of AFLP fingerprinting for the detection of genetic variation in fungi. Mycological Research, London, v.100, n.9, p. 1107-1111, 1996.
9. McDonald, B.A. The population genetics of fungi: tools and techniques. Phytopathology, Saint Paul, v.87, n.4, p.448-453, 1997.

10. Möller, E.M.; Bahnweg, G.; Sandermann,H.; Geiger, H.H. A simple and efficient protocol for isolation of high molecular weight DNA from filamentous fungi, fruit bodies, and infected plant tissues. Nucleic Acids Research, Oxford University Press, v.20, n.22, p.6115-6116, 1992.

11. Pernezny, K. Some common diseases of tahiti lime in Florida. Florida: Tropical Research \& Education Center, 1999. 3p. (Plant Pathology Fact Sheet, PP24).

12. Rehner, S.A.; Uecker, F.A. Nuclear ribosomal internal transcribed spacer phylogeny and host diversity in the coelomycete Diaporthe. Canadian Journal of Botany, Otawa, v. 72, n.1, p.16661674, 1994.

13. Says-Lesage, V.; Roeckel-Drevet, P.; Vigué, A.; Tourvieille, J.; Nicolas, P.; Labrouhe, D.T. de. Molecular variability within Diaporthe/Phomopsis helianthi from France. Phytopathology, Saint Paul, v.92, n.3, p. 308-313, 2002.

14. Scott, K.D.; Pacey, T.; Ablett, E.M.; Lee, L.S.; Henry, R.J. AFLP markers distinguishing an early mutant of flame seedless grape. Euphytica, New York, v.113, n.3, p.245-249, 2000.

15. Timmer, L.W. Diseases of fruit and foliage. In: TIMMER, L.W.; DUNCAN, L.W. Citrus health management. St. Paul: The American Phytopathological Society, 1999, p.107-115.

16. Timmer, L.W. 2000 Florida citrus pest management guide: Melanose. Florida: Florida Cooperative Extension Service, Institute of Food and Agricultural Sciences, University of Florida, 2000. 3p. (Fact Sheet, PP-145).

17. Tohme, J.; Gonzalez, O.; Beebe, S.; Duque, M. AFLP analysis of gene pools of a wild bean core collection. Crop Science, New York, v.36, n.1, p.1375-1384, 1996.

18. Uddin, W.; Stevenson, K.L. Pathogenicity of a species of Diaporthe causing a shoot blight on peach in Georgia and evaluation of possible infection courts. Plant Disease, Saint Paul, v.81, n.9, p.983-989, 1997.

19. Van Der AA, H.A.; Noordeloos, M.E.; Gruyter, J. Species concepts in some larger genera of the Coelomycetes. Mycological, London, v.32, n.1, p.3-19, 1990.

20. Vos, P.; Hogers, R.; Bleeker, M.; Reijans, M.; Van De Lee, T.; Hornes, M.; Frijters, A.; Pot, J.; Peleman, J.; Kuiper, M.; Zabeau, M. AFLP: a new technique for DNA fingerprinting. Nucleic Acids Research, v.23, n.1, p.4407-4414, 1995.

21. Zhang, A.W.; Riccioni, L.; Pedersen, W.L.; Kollipara, K.P.; Hartman, G.L. Molecular identification and phylogenetic grouping of Diaporthe phaseolorum and Diaporthe longicolla isolates from soybean. Phytopathology, Saint Paul, v.88, n.12, p.1306-1314, 1998. 